\title{
Capital social: debates y reflexiones en torno a un concepto polémico
}

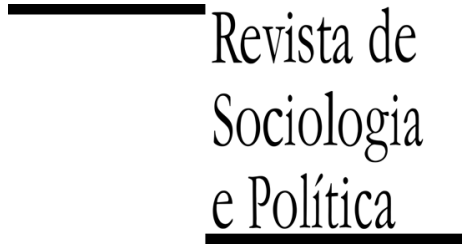

DOI 10.1590/1678-987314225101

\author{
Julieta Capdevielle
}

\author{
RESUMEN
}

Desarrollado en los países capitalistas avanzados, el concepto de capital social -también denominado como redes sociales- adquirió peso en las ciencias sociales latinoamericanas en los años noventa. Los organismos internacionales como el Banco Mundial y el Banco Interamericano tuvieron su influencia en el interés otorgado a este concepto (HINTZE, 2004). El auge que cobró este concepto se debe a que el mismo concentró la atención en las consecuencias positivas de la sociabilidad a la vez que dejó de lado sus rasgos menos atractivos. De este modo, muchas investigaciones sobre capital social no consideraron de manera suficiente los costos del intercambio social ni las relaciones de poder en las que las redes se insertan. El objetivo del presente trabajo busca mapear y problematizar los distintos paradigmas que han abordado este concepto, haciendo hincapié en sus fortalezas y debilidades. Para lo que realizamos um relevamiento bibliografico de diversos autores que se han abocado a investigar a este concepto desentrañando las distintas concepciones de capital social que se corresponden con determinadas perspectivas sobre el orden social. Desde el paradigma sostenido por los organismos internacionales, las relaciones de poder quedan excluidas como elemento explicativo de las prácticas sociales. Es decir, encorsetadas en una mirada de la realidad social que se centra en el orden y en el funcionamiento armonioso de los individuos y de los colectivos, están totalmente ausentes herramientas analíticas capaces de dar cuenta de las fuentes de poder y de conflicto. En contraposición, la noción de capital social que utilizamos se sustentó en la perspectiva teórica bourdieusiana. Matriz teórica que permite contemplar las relaciones de poder y conflicto constitutivas de la sociedad. De este modo, el concepto de capital social sostenido desde la perspectiva de Pierre Bourdieu constituye una herramienta fundamental y superadora de otras perspectivas teóricas.

PALABRAS CLAVE: capital social; poder; dominación; estrategias; conflicto.

Recebido em 25 de Outubro de 2012. Aprovado em 21 de Abril de 2013.

\section{Introducción} empíricos en el campo de las ciencias sociales han confirmado la importancia del capital social como recurso alternativo decisivo que las familias pobres emplean para hacer frente a las necesidades cotidianas y de reproducción social (inter alia Lomnitz 1978; Ramos 1981; Torrado 1982; Bartolomé 1985; Hintze 2004; Gutiérrez 2005a; 2005b; Chávez Molina 2010). Así, una diversidad de investigaciones caracterizaron las redes sociales como relaciones sociales informales y personales entre miembros de diferentes unidades domésticas que intercambian bienes y servicios con poca mediación monetaria. Las redes sociales poseen un lugar destacado dentro de las estrategias de reproducción social de las familias pobres ya que las mismas proveen cierta estabilidad frente a las inseguridades del mercado laboral y al escaso volumen de capital cultural con que cuentan. En otras palabras, siendo sólo uno de los tipos de recursos utilizables, el capital social cobra importancia fundamental en la medida en que se trata de comprender y explicar un conjunto de prácticas que son implementadas por un grupo de familias que poseen un escaso volumen de capital económico y cultural, y que se ven enfrentadas a resolver todas las exigencias de su cotidianidad (Gutiérrez 2008b). 
Por otro lado, numerosos investigadores han estudiado la importancia del capital social en familias pertenecientes a otras clases sociales. Así Montes y Sendón (2008) abordaron el peso que juega el capital social en la búsqueda laboral de las clases medias y altas. En estos sectores la inserción laboral se intentaría por medio de parientes y conocidos más o menos cercanos al grupo familiar con poca o nula incidencia de la escuela. En este sentido, puede sostenerse que el capital social adquiere un papel fundamental para las clases sociales más altas a la hora de insertarse laboralmente, mientras que la educación pierde su papel de garante (Filmus 2001).

Sin embargo, no son muchas las investigaciones que señalan los límites del capital social como parte de las estrategias de reproducción social que las familias pobres despliegan. En este sentido, autores como Míguez (2001) y González de la Rocha $(1999 ; 2005)$ subrayan que las relaciones de reciprocidad no son recursos inagotables. En muchas ocasiones, el costo (en tiempo y dedicación) de participar en las redes sociales tiende a superar los beneficios.

Por otro lado, es importante remarcar que a pesar del intensivo uso del concepto de "capital social" por parte de los cientistas sociales, el desarrollo del concepto está todavía muy lejos de alcanzar un significado unívoco y consensual. Muy por el contrario, la exploración metodológica y de investigación empírica hasta ahora realizada no parece haber acotado debidamente el uso del concepto sino que, por el contrario, lo ha impulsado a veces de manera difusa y sin contornos (Chávez Molina 2010, p.35).

De este modo, existen diferentes concepciones sobre el capital social que se sustentan en paradigmas teóricos y metodológicos diferentes. Algunas perspectivas consideran al capital social como un recurso individual y otras como un atributo de la comunidad, la sociedad o la estructura social (Freyre 2013). En el siguiente apartado nos centraremos en desentrañar los distintos paradigmas teóricos que abordan este concepto.

\section{Paradigmas del capital social: diferencia y aproximaciones}

\section{II.1. El capital social desde los enfoques de la integración social}

Desde el paradigma de la integración social se sustenta una teoría de la acción que privilegia el análisis del consenso, de la integración armónica. Perspectiva de análisis que se puede rastrear hasta los mismos orígenes de las ciencias sociales. Ya a fines del siglo XIX Émile Durkheim señalaba la importancia de las relaciones sociales en la cooperación social como fuente fundamental de la solidaridad en las sociedades modernas (Forni, Siles \& Barreiro 2004). Más allá de las particularidades que tienen las teorías que integran este paradigma, todas comparten una mirada de la realidad social que se centra en el orden y en el funcionamiento armonioso de los individuos y los colectivos, en ninguna de estas "visiones" están presentes herramientas analíticas capaces de dar cuenta de las fuentes de poder y de conflicto, es decir, de las diferencias sociales, del diferente posicionamiento que pueden tener -y tienen- los agentes sociales en cada uno de esos niveles organizativos, por un lado, y las propias organizaciones en relación unas con otras, por otro lado (Gutiérrez 2008a, pp. 33-34).

Siguiendo los aportes de Gutiérrez (2008a) podemos agrupar distintas investigaciones (Coleman 1987; 1988; 1990; Putnam 1993; 1995; Woolcock \& Narayan 2000) sobre el capital social en cuatro "visiones diferentes": la visión comunitaria, la visión de las redes, la visión institucional y la visión sinérgica. Podríamos decir que cada una de estas perspectivas privilegia un nivel organizativo diferente, como aquel que define más certeramente lo que se denomina 
"capital social". Es decir, se hace necesario identificar dos cuestiones íntimamente relacionadas: a) la noción de capital social siempre remite a un cierto nivel de organización social, b) cuál es dicho nivel, cuáles son las unidades que lo forman, cómo se articulan, etcétera, puede ser y es objeto de diferentes puntos de vista (Gutiérrez 2008a, p. 32).

La visión comunitarista sostenida por los organismos internacionales asocia el capital social con la capacidad de la sociedad de auto-gestionarse a través de organizaciones locales tales como clubes, asociaciones y grupos cívicos. Los comunitarios, que se interesan por la cantidad y densidad de estos grupos en una determinada "comunidad" sostienen que el capital social es inherentemente bueno; en consecuencia su presencia siempre tiene un efecto positivo en el bienestar de la comunidad (ibidem).

Los trabajos que se sitúan dentro de la visión de redes intentan subrayar dos cuestiones: por un lado, la importancia que tiene el fortalecimiento de los lazos intracomunitarios como dadores de un fuerte sentimiento de identidad y, por otro, la necesidad de construir lazos intercomunitarios susceptibles de traspasar barreras étnicas, de género, de status socio económico, etc. A los primeros se les suele llamar capital social "que une" (bonding) y a los segundos, capital social "que produce puentes" (bridging). De este modo, el capital social de un grupo o de una "comunidad" para hablar en términos de estos autores, se compondría de distintas combinaciones posibles de estos dos componentes - verticales y horizontales (Guitérrez 2008a, pp. 32-33).

La tercera visión, la visión institucional que privilegia otro nivel organizativo, sostiene que la vitalidad de las redes comunitarias y de la sociedad civil es, en gran parte, el resultado de su contexto político, legal e institucional. Este enfoque sostiene que la capacidad de los diferentes niveles de grupos sociales para movilizarse por intereses colectivos depende, precisamente, de la calidad de las instituciones formales con las cuales funcionan (idem, p. 33).

Por último, la llamada visión sinérgica unifica la visión que privilegia los ámbitos institucionales con aquella que pone el acento en las redes. El objetivo de estos estudios es buscar las condiciones que estimulan sinergias de desarrollo: alianzas profesionales dinámicas, y relaciones entre y dentro de burocracias estatales y diversos actores de la sociedad civil (ibidem).

En síntesis, estas investigaciones se incluyen dentro de una teoría de la acción que privilegia el análisis del consenso, de la armonía de la integración. Es decir, en ninguno de estos estudios están presentes herramientas analíticas capaces de dar cuenta de las fuentes de poder y de conflicto.

\section{II.2. El individualismo metodológico y el capital social}

Desde la perspectiva del individualismo metodológico los fenómenos sociales se explican siempre por la suma de las acciones individuales de los actores . De ello se deriva que el átomo lógico del análisis sociológico es el actor individual, actor que entra en relación con otros (constituyendo un sistema de interacción o un sistema de interdependencia) y que actúa según un cálculo en términos de costo- beneficios, eligiendo el mejor medio para obtener el fin deseado (Boudon 1981). Así, desde esta mirada teórica, se plantea que las raíces de la pobreza están en las desigualdades generadas por el mercado, pero los sectores pobres tienen un potencial de atenuar estas desigualdades por medio de iniciativas personales, utilizando relaciones sociales para compensar su carencia de capital material (Chávez Molina 2010).

Dentro de esta perspectiva encontramos a James Coleman quien inscribe la Teoría de la Acción Racional en el análisis del sistema social, lo que le facilita 
introducir la racionalidad individual en el plano de la acción. Así, para él, los actores generan interdependencia y acciones de intercambio que ocurren en eventos en los que ellos tienen intereses, y estos eventos pueden estar totalmente o parcialmente bajo el control de los actores (idem, p. 38). Desde esta perspectiva Coleman define al capital social como aquello que es productivo, y hace posible el logro de ciertos fines que serían inalcanzables en su ausencia, por ejemplo un grupo cuyos miembros manifiestan confiabilidad, y confían ampliamente unos en otros, estarán en capacidad de lograr mucho más en comparación con un grupo donde no existen la confiabilidad ni la confianza (Coleman 1990).

De este modo para Coleman el capital social es un medio o un recurso que: facilita a los individuos la consecución de sus propios intereses; es inherente a la estructura de las relaciones sociales; a partir de la realización de favores, el capital social adopta la forma de obligación y es a través de ella que el individuo alcanza sus propios objetivos, procurando que la retribución se produzca en el momento más conveniente para él; y (por último), la posibilidad de aparición de esta forma de capital social queda sujeta a diversos factores, entre ellos el grado de confiabilidad del entorno social, las necesidades actuales de los individuos y el grado de cercanía de las redes sociales (Forni, Siles \& Barreiro 2004). Es así que, el concepto de "capital social", de Coleman, se inserta en la teoría de la acción racional, que lo lleva a plantear las relaciones (que, en realidad, son la suma de acciones individuales) en términos instrumentales, concebidas como elementos del cálculo racional de agentes que buscan explícitamente su propio interés y a partir de la formulación de fines explícitos (Gutiérrez 2008a, pp. 38-39). Por ello, la definición de capital social de Coleman encierra una visión absolutamente utilitarista y unidimensional del capital social, "X es valioso, $\mathrm{X}$ es útil", donde otros aspectos presentes en la interdependencia no "cuentan" o son soslayados en el proceso de la interacción (Chávez Machado 2010, p. 37).

De este modo, las redes se explican, en esta perspectiva, a través de las interacciones concretas y reales entre individuos. Es la interacción la que, en un primer momento, dispone un vínculo y, por lo tanto, es la estructura de esa interacción la que, en principio, contiene elementos que pueden constituir al capital social, porque presupone cooperación y coordinación. La acción de los individuos ocurre en contextos institucionalizados que regulan y dan permanencia a las interacciones. Cuando los individuos se apropian de estos elementos, se constituye el capital social (Coleman 1990). Se desprende de esta cita que las interacciones entre los actores generan su interdependencia, y, en consecuencia, la interacción genera una suerte de estructura para los que participan en ella. En ese sentido, configura un medio donde se desarrolla la acción "que va más allá de la noción del actor aislado" (Gutiérrez 2008a, p. 36).

A su vez, Coleman le da un contenido sustancialista a la noción de capital en general: se trata en definitiva de una 'cosa', en el sentido de algo que se crea y está allí, independientemente de cuál pueda ser la modalidad de su utilización. Mientras el capital físico es totalmente tangible, y el humano ya lo es menos por estar incorporado en las habilidades y el conocimiento adquiridos por un individuo, el capital social es aún menos tangible, al estar incorporado en las relaciones entre las personas (Baranger 2000, p. 11). Finalmente, señala Baranger, en el concepto estrechamente económico de Coleman no está en absoluto presente la idea de dominación.

Desde una perspectiva similar a la de Coleman (1990), Putnam (1993; 1995) plantea al capital social como un instrumento de análisis macro, como un atributo de las comunidades, y no ya simplemente como un recurso de carácter individual. Desde esta perspectiva el capital social se define como "aspectos de la organización social tales como confianza, normas y redes, que pueden mejorar la eficiencia de una sociedad al facilitar la acción coordinada (Putnam 
1993, p. 167). Asimismo, la confianza, la reciprocidad, las redes sociales y, fundamentalmente para este autor, el compromiso cívico, comprenden las dimensiones del fenómeno que logra explicar por qué ciertas comunidades alcanzan mayores niveles de desarrollo económico y democrático que otras. El eje central de la obra de Putnam gira en torno a comprender los problemas que presenta la acción colectiva. Específicamente, trata sobre la tendencia comunitaria hacia la cooperación en pos del bien común.

Ahora bien, respecto a las formulaciones de James Coleman y Robert Putnam es importante señalar que ambos autores difieren acerca de dónde buscar los elementos que definen centralmente el capital social: en los individuos o en la sociedad. Así, mientras para Coleman, el capital social consiste fundamentalmente en recursos insertos en las estructuras de relaciones sociales; para Putnam el acento está puesto en la confianza, en las normas de reciprocidad y en el compromiso cívico, dimensiones más específicamente relacionadas con los actores sociales (Gutiérrez 2008a, pp. 34-35). Esta distinción entre los diferentes abordajes ha sido denomina "primacía de la estructura" $v$ s. "primacía de la subjetividad". O "perspectiva estructural" del capital social (BourdieuColeman) vs "perspectiva disposicional o cultural" (Putnam-Fukuyama) (Hintze 2004). Sin embargo, la "estructura" de Coleman, sigue estando del lado de la acción individual y, con ello, permanece encerrada en una de las alternativas de la falsa oposición entre estructura y acción, entre objetivismos y subjetivismo. El "más allá de la noción del actor aislado" no es más que la interacción con otro actor.

"Aquí no se trata de relaciones independientes de la conciencia y de la voluntad de los agentes, sino de una "estructura" (más correctamente sería decir interacción) que implica la suma de las acciones de los actores sociales individuales, tal como la predica el individualismo metodológico" (Gutiérrez 2008a, p. 37).

Lo que es evidente es que en el concepto estrechamente económico de Coleman no está en absoluto presente la idea de dominación propia de Marx del capital entendido como "poder de gobernar el trabajo y sus productos" (Marx 1989, p. 33). Para Coleman, en cambio, el capital social es un bien público del que todos los miembros de una sociedad podrán beneficiarse por igual. En efecto, el capital social en general no es un recurso fácilmente apropiable e intercambiable; en tanto es un atributo de la estructura social en la que el individuo está inserto, no es propiedad privada de ninguna de las personas que se benefician de él (Coleman 1990, p. 315).

Si consideramos lo propuesto desde esta perspectiva, podemos plantearnos como una duda a modo de crítica, ¿Qué es el bien común? ¿A qué se refiere con esta idea? ¿Podemos afirmar que existe algo como tal en la sociología a partir de los aportes de Carlos Marx? Y, por otro lado, ¿a qué se refiere con "participantes del capital social”? ¿Eso implica que el capital social comunitario es una entidad que existe allí y que los sujetos deciden si quieren participar o no? (Freyre 2013). La definición de capital social comunitario (desde la perspectiva neoinstitucionalista) que se desprende de Putnam y de North -según la cual el capital social sería lo que produce cooperación y civismo, de modo que si hay civismo habrá capital social- ha sido correctamente calificada de tautológica o circular (Portes 1998). Siguiendo estos planteos, cabe preguntarse acerca de si el capital social es equivalente a democracia o a civismo, y bajo este supuesto, si puede existir capital social en contextos autoritarios o dictatoriales (Freyre 2013).

Por último, desde el paradigma sostenido por los organismos internacionales como el Banco Mundial y el Banco Interamericano el concepto de capital social se volvía fructífero en tanto que el mismo iluminaba las posibilidades de una sociedad autoorganizada y autorregulada para resolver las fallas del 
mercado sin necesidad de una intervención estatal (Hintze 2004, p. 148). Así, el impulso que cobró este concepto se debe a que éste concentró la atención en las consecuencias positivas de la sociabilidad a la vez que deja de lado sus rasgos menos atractivos. Segundo, el concepto así utilizado mostró como las maneras en que formas no monetarias de intercambio pueden ser fuentes de poder e influencia tan importantes como el volumen de las acciones o la cuenta bancaria. El carácter potencialmente fungible de diversas fuentes de capital disminuye la distancia entre las perspectivas sociológica y económica y simultáneamente despierta la atención de los planificadores de políticas que buscan soluciones no económicas y menos costosas a los problemas sociales (Portes 1999, p. 244).

De este modo, muchas investigaciones sobre capital social no se consideran de manera suficiente los costos del intercambio social (Arriaga 2005). Aspectos que sí fueron tomados en cuenta por Portes (1999). Este autor remarca algunos efectos negativos asociados al capital social: exclusión de los extraños; reclamos excesivos a los integrantes del grupo; restricciones a la libertad individual: que reducen la privacidad y la autonomía; normas niveladoras hacia abajo: cuando la solidaridad grupal se consolida con la experiencia común de la adversidad y la oposición a la sociedad predominante. Esta solidaridad es fundada en la experiencia común de subordinación y por ello, perpetúa la situación misma que condena.

Según Portes, el capital social no es lo mismo que los recursos conseguidos a través de él y distingue entre poseedores de capital social, fuentes de capital social y recursos en juego.

Por otro lado, el autor reconoce 3 funciones básicas del capital social. Como fuente de control social: permite la imposición de reglas para hacer innecesarios los controles formales o abiertos. Como fuente de apoyo familiar: permite transferencias hechas de padres a hijos y apoyo familiar como contrapeso de la pérdida de lazos comunitarios. Como fuente de beneficios a través de las redes extrafamiliares: habilita bienes ganados gracias a la pertenencia a redes comunitarias y de otro tipo.

De este modo, su planteo resulta interesante puesto que nos permite comprender como desde algunas perspectivas, el capital social es analizado como un elemento que contribuye a reforzar valores y normas que favorecen la reproducción del orden social. Así, el capital social serviría a las funciones de control social. Frente a estos planteos cabe preguntarnos si el capital social refuerza la tendencia al equilibrio social ¿Qué lugar tiene la transformación social en este esquema? (Freyre 2013).

Por otro lado, cabe mencionar que en la bibliografía sobre el tema existen otras clasificaciones que hacen referencia a los diferentes grados de la intensidad de capital social y distinguen entre: capital social de unión ("bonding" como relaciones sociales estrechas y frecuentes), de vinculación ("linking" relaciones sociales medianamente estrechas) y de puente ("bridging" correspondiente a las relaciones sociales asimétricas y el contacto personal limitado) (idem). Así, en las perspectivas analizadas, encontramos posturas que ponen el énfasis en la interacción, los vínculos y las dinámicas que se generan en los intercambios entre los sujetos sociales.

En estas definiciones del capital social las relaciones de poder quedan excluidas como elemento explicativo de las prácticas sociales. Son teorías de la acción que privilegian el análisis del consenso, de la integración, de la armonía. Es decir, incluidas en una mirada de la realidad social que se centra en el orden y en el funcionamiento armonioso de los individuos y de ellos colectivos, en ninguna de estas "visiones" están presentes herramientas analíticas capaces de 
dar cuenta de las fuentes de poder y de conflicto, es decir, de las diferencias sociales, del diferente posicionamiento que pueden tener -y tienen- los agentes sociales (Gutiérrez 2008a, pp. 33-34).

A modo de cierre de este apartado podemos decir que en estas concepciones de capital social se corresponden con las perspectivas que se ubican dentro de aquellas teorías que comprenden al orden social desde la integración y el equilibrio social que se genera a partir de la interacción de los individuos, de modo tal que la confianza y la reciprocidad se constituye para aquellos autores, como el motor de las prácticas sociales (Freyre 2013).

\section{El capital social desde la perspectiva estratégica de la acción}

\section{III.1. El Capital social: poder y relación en de Pierre Bourdieu}

Por el contrario, la noción de capital social que utilizamos se sustenta en la perspectiva sociología de Pierre Bourdieu, perspectiva que permite contemplar las relaciones de poder y conflicto. Así, este enfoque estratégico de la acción social habilita una lectura crítica de la realidad social.

Frente a nociones sustancialistas del capital, Bourdieu propone un concepto que remite claramente a Marx y sostiene que el capital, antes que una cosa, es una relación social (Gutiérrez 2008b). De este modo, Bourdieu mantiene una concepción de capital que es eminentemente relacional en todas sus especies. Y esto es extensible a su concepción del capital social. Así, el capital social es definido como

“conjunto de recursos actuales o potenciales que están ligados a la posesión de una red duradera de relaciones más o menos institucionalizadas de interconocimiento y de inter-reconocimiento; o, en otros términos, a la pertenencia a un grupo, como conjunto de agentes que no están solamente dotados de propiedades comunes (susceptibles de ser percibidas por el observador, por los otros o por ellos mismos) sino que están también unidos por lazos permanentes y útiles" (Bourdieu 1980, p. 2).

En otras palabras, sería el conjunto de relaciones sociales que un agente puede movilizar en un momento determinado, que le pueden proporcionar un mayor rendimiento del resto de su patrimonio (los demás capitales, económico y cultural especialmente) (Gutierréz 2005b, p. 13). Así el capital social es presentado como un multiplicador que permitiría explicar diferencias en los rendimientos producidos por el capital económico o el cultural.

Entonces, la red de relaciones es el producto de estrategias de inversión social consciente o inconscientemente orientadas hacia la institución o la reproducción de las sociales directamente utilizables, a corto o largo plazo, es decir hacia la transformación de relaciones contingentes, en relaciones a la vez necesarias y efectivas, que implican obligaciones durables subjetivamente sentidas (reconocimiento, respeto) o garantizadas institucionalmente (derechos); todo ello gracias a la alquimia del intercambio (de palabras, de dones, etc.) como comunicación que supone y que produce el conocimiento y el reconocimiento mutuo (Chávez Molina 2010, p. 36).

Pero a su vez, Bourdieu apunta a la eficacia simbólica y no meramente instrumental de este tipo de capital. El intercambio transforma los objetos intercambiados en signos de reconocimiento $\mathrm{y}$, a través del reconocimiento mutuo de los agentes y el reconocimiento de pertenencia al grupo, produce, construye el grupo y al mismo tiempo determina los límites del grupo: en otras palabras, delimita el espacio más allá del cual el intercambio no puede tener lugar (Gutiérrez 2005c, p. 38). 
En este punto es interesante señalar que, el volumen de capital social que ha logrado acumular un agente particular, no sólo depende de la extensión de la red de relaciones que él pude efectivamente movilizar en un momento determinado, sino también los otros capitales: económico, simbólico o cultural de cada uno de los agentes que participan en una red (Chávez Molina 2010, p. 36).

Cabe remarcar que, el capital social en tanto fuente de poder, constituye, a su vez, "algo que está en juego" (enjeu), que se intenta acumular y por lo que se está dispuesto a luchar. Aquí podemos encontrar diferencias respecto a las perspectivas interaccionistas puesto que en el concepto estrechamente económico de Coleman no está en absoluto presente la idea de dominación, frente a la concepción de Bourdieu, que, remitiendo a la visión marxista, define a las distintas especies de capital como diferentes especies de poder que se distribuyen desigualmente en los distintos campos, generando con ello estructuras de posiciones de dominación- dependencia (Gutiérrez 2005b, p. 12).

Para Bourdieu el capital social no es algo natural, ni tampoco "algo dado socialmente", sino que por el contrario es resultado de una construcción, que supone importantes inversiones materiales y simbólicas y de esfuerzos que implican otros gastos. Su utilidad se expresa en los beneficios materiales y simbólicos (el prestigio, por ejemplo) que permite apropiar y esos beneficios dependen de la participación en la red de relaciones. Así, la construcción del capital social convierte "relaciones contingentes" (vecindad, parentesco y otras) en "relaciones necesarias y electivas" que conllevan obligaciones institucionales, comunicacionales y sentidas (como respeto, amistad, gratitud) (Hintze 2004, pp. 149-150).

Desde esta perspectiva de análisis encontramos diferentes modalidades de capital social -individual, familiar o doméstico y colectivo-comunitario -, cada una de las cuales podrá dar lugar a la conformación de esas diferentes redes (Gutiérrez 2008b). El capital social bajo la forma individual es el que se pone en marcha de manera independiente por algún miembro de la familia que es objeto de análisis: es susceptible de ser identificado, especialmente, a la hora de buscar y conseguir un trabajo. Por otro lado, el capital social familiar o doméstico es la forma que adquiere en el seno de la familia: se trata de un recurso para el grupo en general, y, por ello, son necesarias su acumulación y su mantenimiento, indicando vías estratégicas de acción. Es también el capital de "base" para la implementación de redes que ligan a las familias entre sí. El capital social colectivo, por su parte, puede tomar la forma "informal" de redes que enlazan de diferente manera (es decir, con posiciones diferentes) a las distintas familias y que de ese modo resuelven algunas necesidades cotidianas, o, también, pueden mostrarse institucionalizado bajo la forma de Cooperativa de Vivienda y Consumo, forma jurídica apropiada para canalizar otro tipo de recursos, como los que provienen del Estado o de organismos no gubernamentales (Gutiérrez 2005b, pp. 14-15). Además, pensar en capital social colectivo supone también la hipótesis de la existencia de una lucha por su apropiación (o monopolización) entre los distintos componentes de las redes, lo que implica tener presente la existencia de tensiones y de conflictos, y, con ello, la estructuración y reestructuración de relaciones de poder.

A su vez, es posible distinguir otras modalidades que adquieren las redes. Las redes de intercambio de reciprocidad indirecta especializada: son redes que se instituyen entre pobres y no pobres, quienes intercambian bienes y servicios asociadas a distintas especies de capital, en las que las familias pobres apuestan su capital social colectivo y los no pobres (agentes o instituciones) aportan otras especies de capital (Gutiérrez 2008b); las redes de intercambio diferido intergeneracional: son redes familiares entre familias pobres, que comprometen a la madre como principal productora y/o distribuidora y a los hijos e hijas y a sus 
familias como principales receptores de diferentes circuitos de bienes y servicios (idem); las redes de resolución de problemas: redes en las que circulan recursos en el marco de políticas sociales que compiten o se articulan con redes clientelares (Auyero 2001); y las redes de reciprocidad generalizada: son redes que sustentan parte de las prácticas que llevan a cabo los nuevos pobres para asegurarse recursos de parientes, amigos o conocidos. En ellas son importantes no solamente los recursos y servicios, sino también los significados y juicios atribuidos (Kessler 1998; Gutiérrez 2005a; 2008b).

Cabe agregar, que desde la perspectiva estratégica, las redes a partir de las cuales entender el capital social, no se conciben como relaciones sociales entre sujetos semejantes, iguales, o pares, que establecen intercambios basados en la reciprocidad y confianza, sino por el contrario, se reconoce la existencia de interese, de conflictos de relaciones de poder, como el sustrato en el que se construyen las diferentes redes sociales (Freyre 2013). De este modo, plantear la hipótesis de una distribución desigual de capital social (de relaciones) implica una revisión de la noción de reciprocidad: no es lo mismo movilizar asiduamente la red o de manera puntual, no es lo mismo tener o no tener relación con agentes que ocupan otras posiciones sociales en otras estructuras de sostenimiento y de apoyo, de dominar o no las informaciones útiles para acceder a diferentes mecanismos de obtención de recursos. Todos estos elementos constituyen fuentes desiguales de poder que deben ser tomadas en consideración en el momento de analizar la diversidad de las estrategias de reproducción de las unidades domésticas (Gutiérrez 2004, p. 269).

Así, las redes de intercambio desde esta perspectiva pueden ser simétricas y asimétricas. La reciprocidad vertical sí puede constituirse como una forma de capital social, e incluso es la especie de capital que circula, por ejemplo, en las redes que vinculan a pobres con no pobres (Freyre 2013). A su vez, retomando los aportes de Gutiérrez (2005a), podemos complejizar la noción de reciprocidad desde el concepto de "capital social doméstico" y de "redes de intercambio diferido intergeneracional", puesto que en este tipo de vínculos, la reciprocidad no se actualiza en el mismo intercambio, sino que quien recibe la prestación no está directamente obligado a quien la ofrece, sino a cualquier otro miembro del sistema. Mauss (2009) acuñó el término de "prestación total" para referirse a este conjunto complejo de reciprocidad indirecta.

Por último, nos parece importante remarcar la dimensión estructural y vincular de las redes de intercambio. Dimensiones abordadas en los trabajos de Gutiérrez (2008b; 2011) y Baranger (2004). La dimensión estructural remite a las condiciones objetivas externas (históricamente situadas) y a su relación con aquellos elementos que permiten ubicar a los agentes e instituciones en el espacio social: volumen y estructura del capital (objetivado e incorporado). En esta dimensión estructural -en la que cobra fuerza la tradición estructuralista francesa de la que se nutrió Bourdieu-, lo que importa son las relaciones entre posiciones y no entre individuos (idem, p. 207).

La dimensión vincular consiste, por su parte, en el análisis de las interacciones concretas, de su frecuencia, de la intensidad de los lazos que pudieran crearse, del tipo y calidad de los bienes (materiales o no-materiales) y de los servicios que circulan, etc. Así, el capital social remite también a la existencia de un nivel de relaciones cara a cara. En este nivel si es importante incluir en el análisis elementos que hacen a la subjetividad de los agentes implicados, ligados a trayectorias individuales y a experiencias personales (Gutiérrez 2008b).

De este modo, esta segunda dimensión hace hincapié en las relaciones sociales concretas entre actores sociales específicos. Lo que implica metodológicamente la utilización de una multiplicidad y diversidad de métodos para 
captar las representaciones que los agentes ponen en juego con el fin de captar cómo definen sus prácticas cotidianas, su propia realidad y los constructos que organizan su mundo.

\section{Conclusiones}

El concepto de capital social cobró fuerzas en las ciencias latinoamericanas en los años noventa por la influencia de organismos internacionales como el Banco Mundial y el Banco interamericano de Desarrollo. Desde el paradigma sostenido por estos organismos, el concepto de capital social se volvía fructífero en tanto que el mismo iluminaba las posibilidades de una sociedad autoorganizada y autorregulada para resolver las fallas del mercado sin necesidad de una intervención estatal (Hintze 2004). En esta misma línea, en el año 2000, la Comisión Económica de las Naciones Unidas para América Latina (CEPAL) y la Universidad del Estado de Michigan de Estados Unidos organizaron una conferencia titulada "Capital social y reducción de la pobreza en América Latina y el Caribe: En busca de un nuevo paradigma”. En ella se intentó examinar las aplicaciones del capital social en la reducción de la pobreza como un intento de "empoderar" a los sectores más pobres. Así, el impulso de este concepto se debió a que el mismo concentró la atención en las consecuencias positivas de la sociabilidad a la vez que dejó de lado sus rasgos menos atractivos. Desde esta perspectiva del capital social las relaciones de poder quedan excluidas como elemento explicativo de las prácticas sociales. Es decir, encorsetadas en una mirada de la realidad social que se centra en el orden y en el funcionamiento armonioso de los individuos y de los colectivos, están totalmente ausentes herramientas analíticas capaces de dar cuenta de las fuentes de poder y de conflicto, es decir, de las diferencias sociales, del diferente posicionamiento que pueden tener - y tienen - los agentes sociales (Gutiérrez 2008a, pp. 33-34).

En contraposición, la noción de capital social que utilizamos se sustentó en la perspectiva teórica bourdieusiana. Matriz teórica que permite contemplar las relaciones de poder y conflicto que constituyen la sociedad. De este modo, el concepto de capital social sostenido desde la perspectiva de Pierre Bourdieu se configura como herramienta fundamental y superadora de otras perspectivas teóricas. El capital social bourdieussiano posibilita la construcción de diferentes escenas sociales que habilitan a analizar relacionalmente (en el doble sentido, como estructura y como interacción). Desde esta perspectiva teórica el capital social es un recurso (y, por ello, una fuente de poder) que puede ser aculado, que puede invertirse, que puede perderse y que puede reconvertirse en otras especies de capital, cuando las condiciones estructurales lo permiten. Como recurso, como fuente de poder, el capital social es también un enjeu, una apuesta, algo que está en juego y por lo que vale la pena jugar.

En suma, la perspectiva de Bourdieu acerca del capital social puede sintetizarse así: (i) el capital social opera como un multiplicador que hace en forma instrumental y directa a las probabilidades de valorización de las otras especies de capital; (ii) funcionando como un capital simbólico en cuyos efectos Bourdieu prefiere, las más de las veces), el capital social concurre "por procuración" a producir la unidad interna de la clase dominante; (iii) y, correlativamente, a reforzar su distinción respecto del resto del universo social; finalmente (iv) el capital social existe también bajo la forma de la capacidad incorporada para entablar y mantener relaciones (Baranger 2004, p. 215).

Por último cabe agregar que el énfasis por potenciar el capital social que los organismos internacionales han analizado durante tres décadas, tiende a eludir el problema central de "los pobres": que el núcleo duro de la superación de la 
desigualdad y la pobreza pasa centralmente por la disminución del desempleo, la precarización laboral y por una verdadera redistribución de la riqueza.

Julieta Capdevielle(julietacapdevielle@gmail.com) é professora do Centro de Investigaciones de la Facultad de Filosofía y Humanidades (CONICET), Córdoba, Argentina.

\section{Referencias}

Arriaga, I. 2005. Introducción. In: , ed. Aprender de la experiencia: el capital social en la superación de la pobreza. Santiago de Chile: CEPAL.

Baranger, D. 2000. Sobre estructuras y capitales: Bourdieu, el análisis de redes, y la noción de capital social. Avá, 2, pp. 41-63. 2004. Epistemología y metodología en la obra de Pierre Bourdieu. Buenos Aires: Prometeo libros.

Bartolome, L. 1985. Estrategias adaptativas de los pobre urbanos: el efecto `entropico’ de la relocalización compulsiva In: L. Bartolomé, ed. Relocalizados: Antropología Social de las poblaciones desplazadas. Buenos Aires: Ediciones IDES.

Boudon, R. 1981. La lógica de lo social. Madrid: Rialp.

Bourdieu, P. 1980. Le capital social. Notes provisoires. Actes de la Recherche en Sciences Sociales, 31, pp. 2-3.

Chavez Molina, E. 2010. La construcción social de la confianza en el mercado informal. El caso de los feriantes de Francisco Solano. Buenos Aires: Nueva Trilce.

Coleman, J. 1987. Norms as Social Capital. In: G. Radnitzky; P. Bernoholz, eds. Economic Imperialism: The economic method applied outside the field of economic. New York: Paragon House Publishers.

1988. Social Capital in the Creation of Human Capital. American Journal of Sociology, 94, supplement, pp. 95-121.

1990. Foundations of Social Theory. Cambridge (MA): The Belknap Press of Harvard University Press.

Fiilmus, D. 2001. Cada vez más insuficiente, cada vez más necesaria. Buenos Aires: Santillana.

Forni, P.; Siles, M.; Barreiro, L. 2004. Qué es el Capital Social y cómo analizarlo en contextos de exclusión y pobreza: Estudios de caso en Buenos Aires, Argentina. JSRI Research Report \#35. The Julian Samora Research Institute, Michigan State University, East Lansing, Michigan.

Freyre, M.L. 2013. El capital social. Alcances teóricos y su aplicación empírica en el análisis de políticas públicas. Revista Ciencia, Docencia y Tecnología de la Universidad Nacional de Entre Ríos. Revista Ciencia, Docencia y Tecnología, VOL. XXIV, No 47, pp. 95 - 118.

González de la Rocha, M. 1999. La reciprocidad amenazada: un costo más de la pobreza urbana. Revista Latinoamericana de Estudio del Trabajo, 5(9), pp. 33-50.

2005. México: Oportunidades y capital social. In: I. Arriaga, ed. Aprender de la experiencia: el costo social en la superación de la pobreza. Santiago de Chile: CEPAL.

Gutiérrez, A. 2004. LA teoría de Bourdieu en la explicación y comprensión del fenómeno de la pobreza urbana. In: L.E. Alonso; E.M. Criado; J.L. Moreno Pestaña, eds. Pierre Bourdieu: Las herramientas del sociólogo. Madrid: Editorial Fundamentos.

. 2005a. Pobre, como siempre... Estrategias de reproducción social en la pobreza. Córdoba: Ferreyra Editor.

2005b. ACERCA de la noción de capital social como herramienta de análisis. Reflexiones teóricas en torno a un caso empírico. Revista Perspectivas, 2(2), pp. 7- 26.

2005c. Las prácticas sociales: una introducción a Pierre Bourdieu. Córdoba: Ferreyra Editor.

2008a. El capital social en la pobreza: apuesta, medio y resultado de luchas simbólicas. In: P.I. Pavcovich; D.P. Truccone, eds. Estudios sobre pobreza en Argentina. Aproximaciones teórico metodológicas. Córdoba: Editorial Universitaria Villa María.

2008b. Redes de intercambio de capitales en condiciones de pobreza: dimensión relacional y dimensión vincular. REDES, 14(4), pp. 1-17.

Hintze, S. 2004. Capital social y estrategias de supervivencia. Reflexiones sobre el `capital social de los pobres’. In: C. Danani, ed. Política social y economía social. Debates fundamentales. Buenos Aires: Altamira.

Kessler, G. 1998. Lazo social, don y principios de justicia: sobre el uso del capital social en sectores medios empobrecidos. In: E. De Ipola, ed. La crisis del lazo social: Durkheim, cien años después. Buenos Aires: Editorial Universitaria de Buenos Aires.

Lomnitz, L. 1978. Como sobreviven los marginados. México: Siglo XXI.

Marx, K. 1989. Manuscritos económicos-filosóficos de 1844. México: Grijalbo.

Mauss, M. 2009. Ensayo sobre el don. Forma y función del intercambio en las sociedades arcaicas. Buenos Aires: Katz Editores.

Míguez, D. 2001. La conversión religiosa como estrategia de supervivencia: Los pentecostales y el descenso social durante la "década perdida". Intersecciones en Antropologia, 2, pp. 73-89.

Montes, N.; Sendón, M.A. 2008. Trayectorias familiares y ofertas institucionales. In: G. Tiramonti; S. Ziegler, eds. La educación de las élites: aspiraciones, estrategias y oportunidades. Buenos Aires: Ed. Paidós.

Portes, A. 1998. Social Capital: Its origins and applications in modern sociology. Annual Review of Sociology, 24, pp. 1-24. . 1999. Capital social: sus orígenes y aplicaciones en la sociología moderna. In: J. Carpio; I. Novacovsky, eds. De igual a igual. El desafío del Estado ante los nuevos problemas sociales. Buenos Aires: Fondo de Cultura Económica.

Putnam, R. 1993. Making Democracy Work. New Jersey: Princenton University Press. 
1995. Tunnin In, Tunning Out: The strange disappearance of social capital in America. Political Science and Politics, 28(4), pp. 664- 683.

Ramos, S. 1981. Las relaciones de parentesco y ayuda mutua en los sectores pobres urbanos: un estudio de caso. Buenos Aires: CEDES.

Torrado, S. 1982. El enfoque de las estrategias familiares de vida en América Latina: Orientaciones teórico-metodológicas. Cuadernos del CEUR, 2, pp. 1-50.

Woolcock, M.; Narayan, D. 2000. Social Capital: Implications for development theory, research and policy. The World Bank Observe, 15, pp. 225-249.

\begin{abstract}
Developed in the advanced capitalist countries, the concept of social capital, also known as social media weight-acquired Latin American social sciences in the nineties. International agencies like the World Bank and the Inter played a role in the interest given to this concept (Hintze 2004). The boom that took this concept is that it focused attention on the positive consequences of sociability while aside its less attractive features. Thus, much research on social capital is not sufficiently considered the costs of social exchange and power relations in which the networks are inserted. The aim of this paper to map out and problematize the different paradigms that have addressed this concept, emphasizing their strengths and weaknesses. To what do um bibliographical survey of several authors who have focused on investigating this concept unraveling the different conceptions of social capital that correspond to certain perspectives on the social order. Since the paradigm supported by international organizations, the power relations are excluded as an explanation of social practices. I mean, look corseted in a social reality that focuses on order and the smooth functioning of individuals and groups, are totally absent analytical tools capable of accounting for the sources of power and conflict. In contrast, the notion of social capital we used was based on the theoretical perspective bourdieusiana. Theoretical matrix that allows us to contemplate the power relations and conflict constitutive of society. Thus, the concept of sustained capital from the perspective of Pierre Bourdieu is a fundamental tool overcomes other theoretical perspectives.
\end{abstract}

KEYWORDS: capital; power; domination; strategies; conflict. 